\title{
President's Letter - April 2004
}

\author{
Anna-Maria Rollin
}

$\mathrm{M}$ Y son and daughter gave me a birthday present. They said it was time I learned something, so they gave me a copy of The Universal Home Doctor - Illustrated, published by Odhams Press Ltd, Long Acre, London W.C.2. Curiously, it is undated, but by looking at the list of drugs which they describe as 'new', I would place it in the early 1930s. In keeping with the custom of the time (the General Medical Council had very stringent rules about 'advertising'), the authors are not named. The editor signs his (I assume it must have been a he) introduction simply 'The Editor', and gives his address as Harley Street, London W.1.

This introduction explains that unless all are able to base their mode of living on the recognised rules of health and hygiene, 'we cannot hope to be an A1 nation.' It is claimed that many new facts are included, which have not yet had time to find their way into the standard medical textbooks, and anaesthesia is highlighted specifically in this regard.

I am interested in the subject of patient information, and turned to the relevant section. Fascinating stuff, and even more fascinating to compare it with more recently published patient information on anaesthesia, the Royal College of Anaesthetists booklet 'Anaesthesia Explained' [Lack et al, 2003].

There is a perfectly good definition of anaesthesia as the 'state of unconsciousness or insensibility to pain to which patients are reduced before a surgeon performs an operation on them.' This definition compares very favourably with the description of general anaesthesia as a 'state of controlled unconsciousness' in the College publication. We would, however, hesitate to describe it as the state to which our patients are 'reduced'. There is also a clear explanation of the difference between local and general anaesthesia.

The patient is advised to prepare himself appropriately before the operation. There is not a word about fasting and the dangers of a full stomach. However, 'In the matter of taking an anaesthetic well the patient can help the doctor considerably by overcoming his dread beforehand, and going to the operation with a quiet mind. It is only reasonable to suppose that the patient who enters the operation with a contented and resigned mind will be easier to anaesthetise than the patient who gives way to cowardice at the last moment and struggles against efforts to give him the anaesthetic, which will relieve him of his pain.'

The book takes a pretty robust attitude to risk (which was then, of course, considerably greater than it is now). The College booklet devotes eight pages to risk. The Universal Home Doctor deals with it in one sentence. 'Far more people are killed by accidents in the streets than by anaesthetics, and sensible people do not go through life dreading they will be killed every time they venture out of the house.'

There is an interesting discussion, in the section on premedication, on the recently introduced practice of anaesthetising patients in their beds, 'so that they do not know of the journey to the operating theatre, and do not wake up or remember anything until several hours after everything is over'. While in general the anonymous author seems to approve of this new technique because the patient 'is not frightened beforehand and will sleep for a longer time afterwards', he does acknowledge that more nursing will be required after the operation. I wonder how modern recovery nurses would feel about this particular challenge to their skills.

There is considerable excitement about the new anaesthetic, Evipan, which is injected into a vein and 'is very safe and useful for short operations.'

However, the mainstays of anaesthesia, both for induction and maintenance, are given as nitrous oxide, chloroform, ether and ethyl chloride. I was unaware that ethyl chloride was perfumed with eau de Cologne to make it less unpleasant. There is reassurance about the induction of anaesthesia. 'There is first a semi-conscious state in which the patient feels the world swirling about him and in which he may talk, sing or laugh. 
With a skilled anaesthetist, this only lasts a very short time, perhaps only seconds, and it is quite unnecessary for people to worry themselves, as they frequently do, by thinking that they may behave in an unseemly fashion or use bad language that they would not use in daily life.'

More mundanely, the College booklet simply says 'People usually describe a swimmy, light-headed feeling.'

In comparing the available anaesthetic agents, the book suggests that ethyl chloride might be a more suitable agent in people who lead an outdoor life, very emotional people and chronic alcoholics, who become excited when they are given laughing gas (nitrous oxide). Chloroform, we are informed, has always been considered a safe anaesthetic in Scotland, but in England is looked upon as much more dangerous than ether.

The attitude to the whole business of anaesthesia and surgery might be described as 'bracing'. As for obtaining the patient's agreement to whatever is proposed - there is simply no entry in the book for 'Consent', informed or otherwise.

\section{REFERENCE}

Lack JA, Rollin A-M, Thoms G, White L, Williamson C. Raising the Standard: Information for patients. Royal College of Anaesthetists. London 2003. 